\title{
ELECTROENCEPHALOGRAPHIC MONITORING DURING CARDIAC SURGERY: OBSERVATIONS ON THE EEG RESPONSE TO SEVERE HYPOTENSION
}

\author{
W. E. SPOEREL, M.D., F.R.C.P. $(C)^{1}$
}

THE SAFE CONDUCr of anaesthesia requires that the anaesthetist have at all times reliable information concerning the vital functions of his patient. This is generally obtained by observing the usual indices such as blood pressure, pulse, respiration, eye signs etc. In cardiac surgery, however, hypothermia with arrest of the circulation, extracorporeal circulation, sudden accidental hypotension or cardiac arrest, as well as the anaesthetic procedures used for this type of surgery; alter or suppress basic physiological functions and the foregoing indices become uninterpretable. In this situation the anaesthetist can either resign himself to intelligent guesswork or attempt to retain precise control by observing other functions which remain valid and useful under the changed conditions.

To this end, anaesthetists have taken methods from the physiological laboratory into the operating room, for example, arterial $\mathrm{O}_{2}$ saturation, blood $\mathrm{pH}$, alveolar $\mathrm{CO}_{2}$, etc.; more recently the development of suitable recording machines has made it possible to monitor the electrocardiogram (ECG) and electroencephalogram ' EEG) continuously during surgical operations.

The anaesthetist is particularly interested in the EEG for two reasons: $(a)$ it affords an index of the depth of anaesthesia (see review by Wyke (23); and (b) it-reveals disturbances of cerebral function, especially those due to inadequate cerebral blood flow and to hypoxia which are constant hazards of open heart surgery: For this reason the recording of the EEG has been advocatend in - the anaesthetic management of cases requiring extracorporeal circulation $(13,18)$.

To use the EEG efficiently as an indicator of the adequacy of cerebral blood flow'and oxygenation, some basic factors have to be considerec

(a) Anaesthesia, hypercapnia, hypoxia, hypotension, hypoglycaemia, and hypothermia affect the whole organism and therefore the whole brain. The recording of a single lead is sufficient for practical purposes and a fronto-occipital lead is usually recommended.

(b) The response of the EEG to these disturbances is not specific, that is, the observed changes in frequency and amplitude of waves are similar regardless. of which disturbande is the cause $(4,17)$. A more specific diagnosis may be made by elimination, for example, if the depth of anaesthesia remains unchanged and $\mathrm{CO}_{2}$ accumulation is avoided, then a change in the wave pattern will most likely be due to inadcquatc oxygenation of the brain caused by either hypoxaemia or an inadequate cerebral blood flow.

(c) Any deviation from the normal wave pattern in the EEG can be regarded as a disturbance of the function of brain cells. Cellular function is depressed in two ways:

1Department of Anaesthesia, University of Western Ontịio, London, Ontario. 
(i) By introduction of agents, such as anaesthetics, that deppress the function of cerebral cells. The gradual changes in electrical activity which results have been classified according to the depth of anaesthesia (7), and it has been shown that there is a good correlation between the blood level of an anaesthetic agent and the empirically designated EEG level (9). An increase in arterial $\mathrm{CO}_{2}$ tension appears to have a similar effect $(6)$. The various anaesthetic agents and $\mathrm{CO}_{2}$ have a summative effect on the EEG, that is, the addition of a second agent will give an EEG pattern similar to that expected from an increase in concentration of the first anaesthetic agent.

(ii) By reduction of the supply of substances essential to normal function. Oxygen and glucose, two most important substances for normal cellular function, have to fall below a critical level (12) before characteristic EEG changes occur. This critical level is considerably below the normal: for example, in the experimental animal a reduction of the $\mathrm{O}_{2}$ saturation in the jugular vein to 30 per cent (12), or in the arterial blood to 40 per cent $(6)$. During surgery in man, EEG changes have been observed at an arterial $\mathrm{O}_{2}$ saturation of 70 per cent when produced rapidly (17), and typical EEG signs have been reported in conscious man breathing 100 per cent $\mathrm{O}_{2}$ at a barometric pressure of $68 \mathrm{~mm}$. $\mathrm{Hg}$. (16) or from mixtures containing 7.8-11.4 per cent $\mathrm{O}_{2}(8)$ : In controlled hypotension in man, no EEG changes were seen above a systolic pressure of $50-60 \mathrm{~mm}$. $\mathrm{Hg}$ (15). A hypoglycaemia of $50 \mathrm{mg}$. per cent was required to próduce EEG manifestations (12), but below such a critical level a small further reduction caused marked EEG changes. Disturbances of this type appear to have a summative effect, that is, a moderate hypoxaemia in the presence of a moderate hypotension may result in EEG changes, although either of these disturbances alone would not produce EEG signs. However, anaesthesia and hypoxia do not appear to have a summative effect (17), that is, a greater degree of hypoxia is required to produce recognizable EEG manifestations in deep than in light anaesthesia.

(d) Whether a disturbance of the cerebral oxygenation is due to a low $\mathrm{O}_{2}$ saturation fanoxic anoxia) or to a low blood flow (stagnant. hypoxia) cannot be determined accurately at all times under clinical conditions. The EEG response to both eonditions is identical, and evidence obtained with both hypoxia and severe hypotension has been used in support of the present interpretations.

\section{Material and Methods}

In 25 patients, ranging from 7 to 50 years of age the EEG (fronto-occipital lead) and the ECG (lead II) were recorded with a direct writing instrument .(Schwarzer Cardioscript S4)-during surgery. In 13 of these patients open intracardiac operations were done, using a Pump-Oxygenator Model "Mark ICooley." Two other patients were operated under hypothermia. Ten patients underwent a mitral valvulotomy. In all cases of extracorporeal circulation and hypothermia and in three cases of mitral valvulotomy, direct arterial pressures were continuously recorded from the radial artery. The arterial $\mathrm{O}_{2}$ saturation was determined at intervals using a $\mathrm{Kipp}$ oximeter.

Anaesthesia was induced with sodium pentothal and in 22 patients maintained with nitrous oxide: oxygen, Demerol ${ }^{B}$; or Leritine In the remaining three, it was maintained with ether or cyclopropane; d-tubocurare or Anectine were used as relaxants. Respiration was controlled while the thorax was open; a mechanical ventilator (Bennett Assistor) was used in 12 of the patients. 
In each patient only the first appearance of EEG changes that were considered due to hypotension has been taken into consideration since subsequent changes coincident with repeated periods of hypotension often require a different interpretation. It was assumed that an arterial $\mathrm{O}_{2}$ saturation of 90 per cent or more during extracorporeal circulation would exclude hypoxaemia as a cause of the EEG changes observed in these patients.

\section{Onservations and. Discussion}

\section{The EEG Response to Hypotension}

A typical EEG response to slowly progressing hypotension (8) is shown in Figure 1 ; in this patient extracorporeal circulation had been started shortly before. During the period of recording, the blood pressure fell slowly from$44-50$ to $35 \mathrm{~mm}$. Hg. With this fall in blood pressure, the normal EEG pattern of light anaesthesia, characterized by fast waves $(20-30 /$ sec. $)$ and an amplitude of 30-50 microvolts, as seen in the left upper part of Figure 1, changed into a slow wave pattern with an increased amplitude. These slow waves (5-7/sec.), at first fairly regular, became irregular. Finally very slow, large waves dominated (1-2/sec.) and these persisted until it was possible to raise the blood pressure. A further fall in blood pressure would have caused a reduction in amplitude and
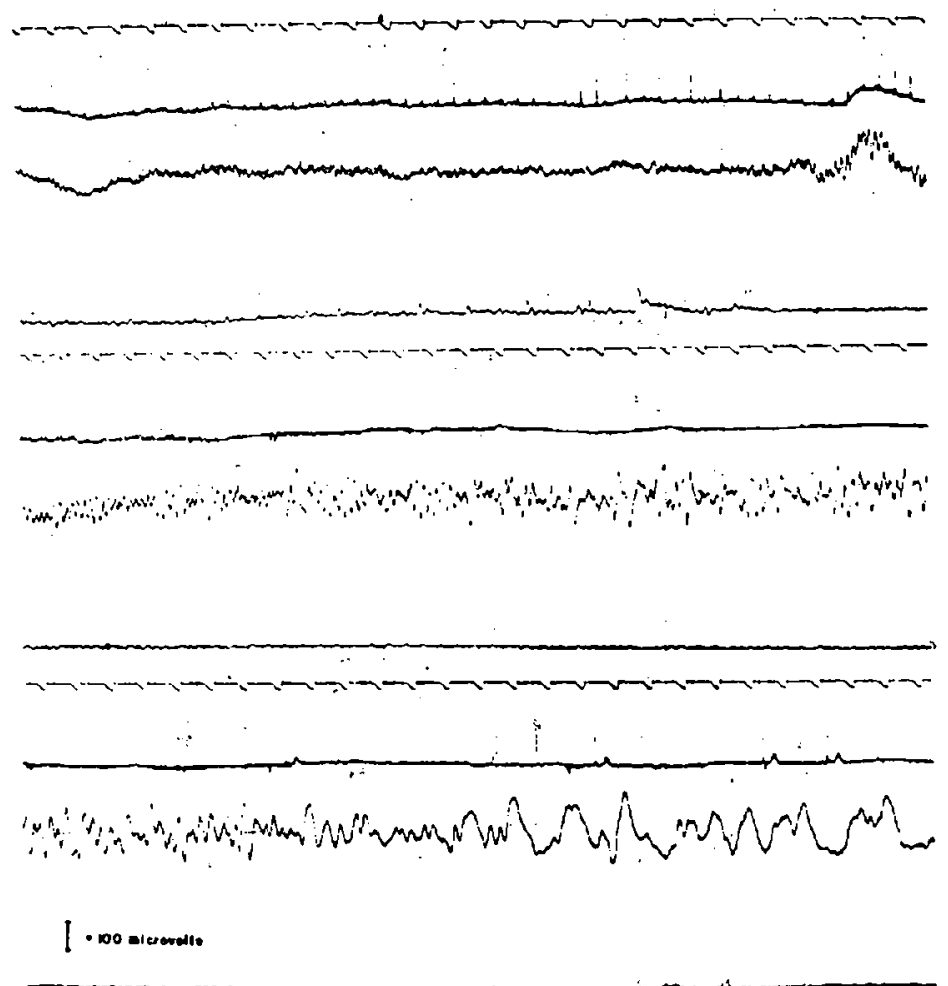

Ficure 1. EEG response. to hypotension-extracorporeal circulation. Continuous record-top to both $m$ : time marker: 1 sec.; ECG lead II, EEG, arterial blood pressure. Centre: Acetylcholine arrest. Notc: Change in wave pattern upper right. The occurrence of irregular slow wav's of higher amplitude (centre) and large very slow waves (bottom right). A gradual fall in blood pressure can be recognized (upper right side: $46-50 \mathrm{~mm}$. $\mathrm{Hg}$; lower right side: $35 \mathrm{~nm} . \mathrm{Hg}$ ). 
more pronounced slowing, leading to a "flattening," that is, a wavy line without any recognizable pattern, and finally a straight line reflecting the disappearance of any cerebral electrical activity (Fig. $3 B$ ).

This record shows a close similarity to the EEG changes seen in anaesthesia alone (7). A correlation between the blood level of anaesthetic agent and EEG pattern has been demonstrated ( 9 入 It is not possible to correlate blood pressure and EEG changes for the following reasons. The critically low level of blood pressure necessary to produce EEG changes depends not only on individual yariations and on age (14) but also on the character of the fall in blood pressure (19). In general, the critical level at which grossly recognizable EEG changes occur is about $50 \mathrm{~mm}$. $\mathrm{Hg}(4,15,19)$. In this series the first EEG changes were observed between 40 and $60 \mathrm{~mm}$. Hg. A yery rapid ifall in pressure căn produce changes at a higher level (19). With drug-induced hypotẹnsion of a slowly progressing type the blood pressure has been observed to fall as low as $36 \mathrm{~mm}$. Hg without causing a change in the EEG (15). In conscious patients, arterial pressures of 29 to $80 \mathrm{~mm}$. Hg have been achieved with hypotensive agents before clinical signs of cerébral anoxia became prominent; the higher any preceding hypertension the higher was the pressure at which the signs appeared $(10)$.

There appears to be a certain degree of adaptation to hypotension as well as hypoxia, presumably brought about by changes in cerebral blood flow and vascular resistance. The return of the EEG pattern towards normal in spite of persistent hypotension (16) or a slowly declining $\mathrm{O}_{2}$ saturation (18) has been observed.

The failure of supply of $\mathrm{O}_{2}$ to the brain is the critical factor in the production of the EEG changes that are important to the anaesthetist. If the oxygen-carrying power of the blood is adequate, and this can be measured or estirnated reliably, then the cerebral blood flow is the important variable. Therefore, it is very likely that the-EEG changes would correlate better with a critically low blood flow than with a certain level of hypotension. Such a relationship was established for clinical signs of hypoxia which were seen to appear with a cerebral blood flow of about $30 \mathrm{ml} . / 100 \mathrm{cc}$. of brain $(10,21)$.

The additive effects of hypotension and hypoxia on the EEG were demonstrated by one of our patients. Large slow waves were observed at a blood pressure of $70 \mathrm{~mm}$. $\mathrm{Hg}$ about three minutes after the beginning of extracorporeal circulation. An immediate sample showed that the arterial $\mathrm{O}_{2}$ saturation was only. 69 per cent and subsequently an insufficient flow of $\mathrm{O}_{2}$ to the bubble oxygenator was found and corrected. About three minutes later, although the blood pressure had not changed, the normal EEG activity returned.

A response similar to the one shown in Figure 1 was seen in twelve of our patients. With one exception, the EEG charges were always related to a critically low bloọd pressure. Severe hypotension always developed shortly after the beginning of extracorporeal circulation. Even -with a low-flow technique, as in our cases, the blood pressure usually stabilized and often rose after about three to five minutes although the output of the pump-oxygenator was not increased. This stabilization or rise probably represents a compensatory adjust- 
ment of the patient's peripheral circulation. The EEG usually reflected these falls of arterial pressure below the critical level for adequate cerebral circulation. In the one patient in whom the blood pressure did not fall below. $55 \mathrm{~mm}$. $\mathrm{Hg}$, the EEG remained unchanged.

It has been thought that the perfusion of the brain with blood. at room temperature is responsible for a transient slow wave pattern which appears shortly after the beginning of extracorporeal circulation, (22). The present observations do not support suah, a view, the appearance of slow waves was always associated with a critically low arterial pressure.

A somewhat different response of the EEG to hypotension has been occasionally observed. In twa cases of valvulotomy, although slow waves did not appear, there was a rapid decrease in amplitude and a temporary flattening of the EEG (Fig. 2).



Figure 2. Mitrat-stenosis: rapid depression of amplitude and flattening of EEG without distinct changes in frequency.

A decrease in amplitude of the EEG without significant slowing has been considered to be an early response to hypoxia (17) and has also been the predominant sign observed in a study of drugrinduced hypotension (15). Under these conditions this was succceded by a slow wave pattem. On the other hand, others have observed a depression of amplitude and flattening without the appearance of distinct slow waves following total occlusion of the blood supply to the brain (2) or cardiac asystole (1). Anoxia in rats, produced by rapid decompression, also produced a decrease in voltage and flattening of the EEG without the appearance of slow waves (20). Schallek and Whalz (19) were ablo. to demonstrate that the speed of development of hypotänsion can determine the response: a sudden fall in pressure produced flatfening immediately; a gradual fall produced slow waves first.

The following observations underline this importance of the suddenness of onset of hypotension to the EEG response. A rather rapid fall in blood pressure shortly after the beginning of extracorporeal circulation produced slow waves (Fig. 3A) similar to those shown in Figure 1, but only briefly. Occlusion of the cardiac inflow under hypothermia produced an even briefer episode of slow waves with only a slight increase in voltage, followed by flattening and electrical silence (Fig. 3B). Sudden cessation of the circulation brought about by the surgeon's finger during a mitral valvulotomy, resulted in a depression of the EEG without slow waves (Fig. 3C).

This latter response (Figs. 2, 3C) has always been observed in patients or experimental animals under anaesthesia; only one report of similar EEG changes 

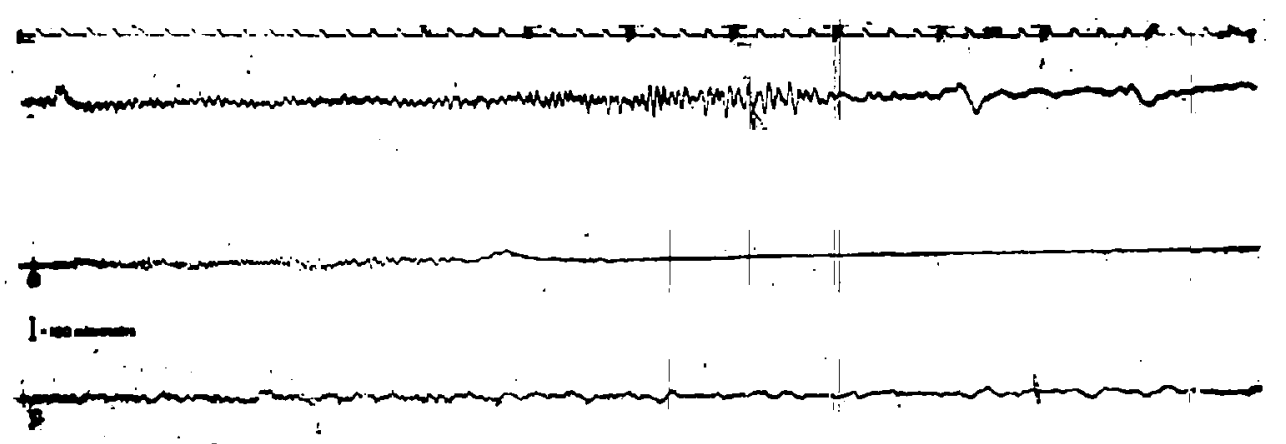

Figune 3. EEG response to reduction of cerebral bloodflow. Top (A): moderately rapid blood pressure fall during extracorporeal circtulation; note the distinct slow wave pattern preceding flattening of the EEG.-Middle $(B)$ : interruption of cardiac inflow under hypothermia ( $31^{\circ}$ C.). Bottom (C): sudden extreme hypotension during mitral valvulotomy. Slow wave pattern absent. Time marker: 1 sec.

in a conscious patient has been found (3). Cardiac asystole in conscious patients, however, resulted in a slow wave pattern (12).

\section{The Time Relation between Sudden Hypotenstyf. Hypoxta AND THE APPEARANCE OF EEG SigNS}

To demonstrate the time relation between the onset of severe hypotension and/or hypoxia, a record of the ECG, EEG, and blood pressure (radial artery) during a mitral valvulotomy is presented (Fig. 4). The entrance of the surgeon's finger into the mitral orifice was marked by the appearance of extrasystoles and a sharp fall in blood pressure. About ten seconds after the beginning of the hypotensive period, large slow waves appeared in the EEG, the blood pressure returned to normal, and only eight seconds later a normal EEG pattern had been restored. A second hypotensive episode was interrupted after seven seconds by three beats with a normal blood pressure, and no definite EEG changes appeared. This brief restoration of blood flow was apparently adequate to prevent EEG changes for another ten seconds. Then the large slow waves reappeared only to disappear when the blood pressure was eventually restored.

Normally the brain contains at any given moment about $7 \mathrm{ml}$. of oxygen which are used up in about ten seconds (14). Sudden cessation of the heartbeat due to vagal stimulation produced EEG changes only after the time equivalent of at least seven beats had elapsed (12). A time interval of four to six seconds was seen in man between the drop in arterial oxygen reflected in the Ear. Oximeter and EEG changes during experimental hypoxia (17). This slight delay in the effect of hypoxaemia on the EEG is similar to that observed in the foregoing clinical case.

Theoretically, breathing of pure $\mathrm{O}_{2}$ before the onset of a critically low blood. pressure should delay the appearance of EEG signs for only a few seconds. A moderate degree of hypoxia before the onset of hypotension should hasten the onset of EEG changes.

For practical purposes such a time lag is of very little significance, and it can be stated that a fall of blood pressure below a critical level is almost immediately 


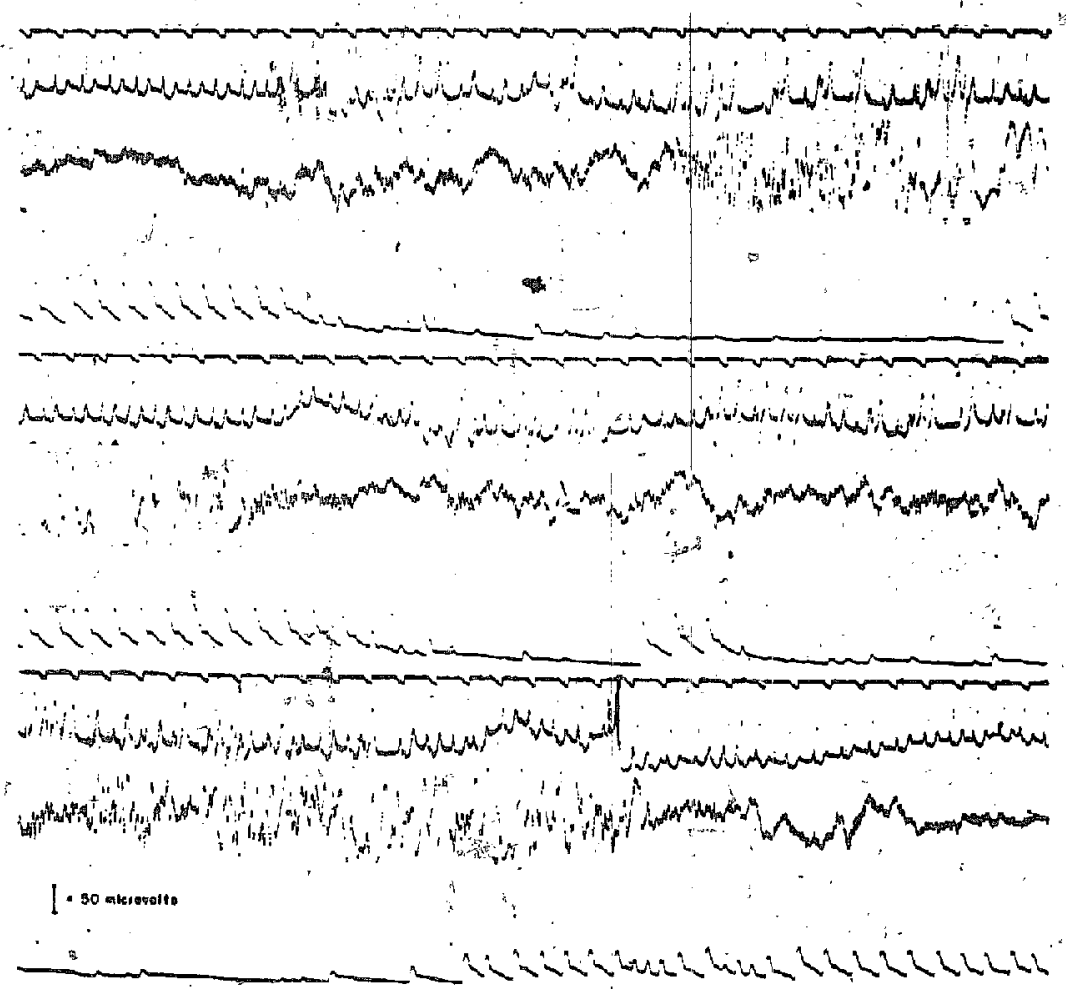

Frgune 4. Mitral valvulotomy-continuous record. Top to bottom: time marker 1 sec, ECG, EEG, "arterial pressure. Occlusion of mitral orifice by surgeon results in sudden hypotension which is followed by EEG changes (top) within 10 sec. The persistence of pulse waves indicates that there is still some blood flow. Return of blood. pressure reverts EEG changes completely.

reflected in the EEG. EEG changes can apparently be delayed, at least temporarily, however, by an intermittent although brief/ restoration of blood flow.

\section{Cerebral and Cardiac Tolerance to Hypotension}

It is reasonable to assume that the appearance of EEG changes during a period of hypotension signifies a disturbance in cerebral function due to hypotensive hypoxia. The absence of abnormal changes during hypotension provides reasonable evidence that the brain can tolerate the existing hypotension without ill effect. The question arises whether or not the rest of the organism can also tolerate such a hypotension.

The only other organ in which acute disturbances in function can be detected is the heart. In acute fatal anoxia in animals, it was always found that EEG changes occurred much earlier than ECG changes (20). This could mean either that the time lag after the onset of the critical degree of hypoxia or hypotension is gyeater for the heart than for the brain, or that the heart can tolerate a greater degree of these deficits without embarrassment. In general, the heart appears less sensitive than the brain to hypoxia.

Although this may be true for the normal heart, the diseased heart may be more vulnerable. This is demonstrated by the record of a patient with a grade 


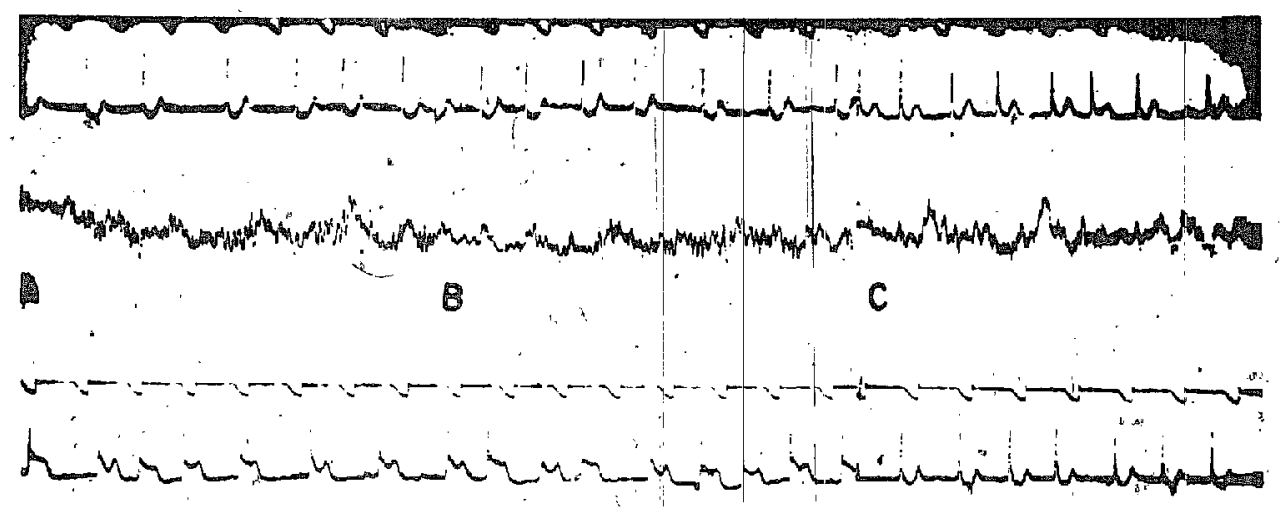

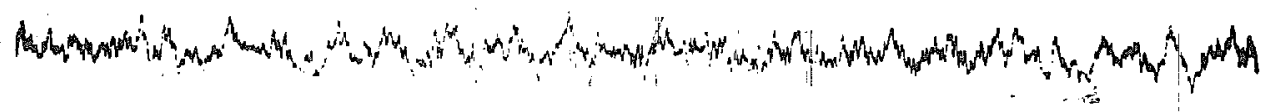

- I. 100 mierovolfs

E.

Figure 5. ECG changes indicating myocardial hypoxia without EEG changes. (Mitral valvulotomy). Top to bottom: time marker (1 sec.) ECG, EEG. A Immediately before valvulotomy. $\dot{\mathrm{B}}$. Approximately 1 min. after completion of intracardiac procedure, blood pressure $60 \mathrm{~mm}$. $\mathrm{Hg}$. C. 2 min. after B, blood pressure approximately $60 \mathrm{~mm} . \mathrm{Hg}$; slight elevation $\mathrm{ST}$ segment. D. $2 \mathrm{~min}$. after C, blood pressure unchanged, marked elevation ST segment. E. $3 \mathrm{~min}$. after D, $10 \mathrm{mg}$. Vasoxyl was given intravenously $2 \mathrm{~min}$. before; blood pressure $100 \mathrm{~mm}$. $\mathrm{Hg}$.

III mitral stenosis (Fig. 5). Following the valvulotomy in this case the blood pressure remained at about $60 \mathrm{~mm}$. Hg systolic (indirect). During this period, no significant EEG changes were seen, but ECG signs of 'myocardial hypoxia developed (Fig. 5C, D); the high elevation of the ST segment disappeared promptly on the restoration of a normal blood pressure (Fig. $5 \mathrm{E}$ ).

Despite the usual greater sensitivity of the brain (EEG) to hypotensive and other forms of hypoxia, one should not conclude that other organs, particularly if they are diseased, are always safe if cerebral electrical activity is mantained.

\section{Conctivsion and SÚmMany}

The electrical activity of the brain represents function of the cortex and changes of these cortical potentials or their disappearance indicate a disturbance sèvere enough to alter or abolish the function of cerebral cells. Changes of the normal EEG pattern occur when the $\mathrm{O}_{2}$ supplyl to the brain has reached a critically low level, owing to either an insufficient blood flow or a low $\mathrm{O}_{2}$ saturation. Although several factors can produce a similar sequence of events in the EEG, it is possible in most instances to exclude a number of these variables and thus determine the most likely cause for the altered EEG pattern.

- In cardiac surgery, where episodes of reduced blood flow frequently occur, the EEG is a useful instrument to warn the anaesthetist that a vital function is threatened, providing its limitations, which have been discussed, are taken into accônt. This warning comes late; only a severe degree of hypotension or hypoxia 
will produc EEG manifestations. But these signs occur some time before it is too late to prevent irreversible damage and they may be the only indication to the anaesthetist of the critical state of his patient. During extracorporeal circulation, where many of the usual vital signs fail, the EEG appears to be the most váluable indicator of an adequate cerebral circulation, .. which can be readily observed and recorded.

In the presented series of cases, two types 'of EEG responses to hypotension have been observed: (i) a pattern of large slow waves, leading to depression of the amplitude and flattening of the EEG; and (ii) a rapid depression of the normal waves, lezding to flattening without the appearance of slow waves.

Observations have been presented which seem to indicate that the suddenness of onset of hypoxia or hypotension is responsible for the type of response. There may also be a difference depending on whether such a disturbance occurs in a conscious or anaesthetized patient.

The sequence of events during a mitral valvulotomy was used to demonstrate the time relation between the onset of hypotension and the appearance of EEG signs. The delay of about ten seconds is probably determined by the circulation time and by the existing state of oxygenation.

During a period of hypotenşion in a patient undergoing a mitral valvulotomy electrocardiographic signs of myocardial ischaemia were seen without EEG changes: Although the brain is usually more sensitive to hypoxia than the heart, this observation demonstrates the markedly reduced tolerance to hypotension of the diseased heart. It is, therefore, concluded that a degree of hypotension that fails to produce EEG changes cannot generally be regarded as safe for the whole organism.

\section{ACKNOWLEDGMENTS}

The author wishes to express his thanks to Professor J. A. F. Stevenson, Head of the Department of Physiology, University of Westerm Ontario, for his encouragement and constructive criticism, to Victoria Hospital (Superintendent Dr. C. J. Kirk) for the provision of the equipment, and to Mr. B. Forbes for techniçal assistance. The co-operation of Dr. J. C. Coles, Department of Surgery, and the members of the Department of Anaesthesia, was much appreciated.

\section{RÉSUMÉ}

L'activité électrique du cerveau atteste une fonction corticale et les changements de ces potentiels corticaux ou leur disparition indiquient des. perturbations assez importantes pour modifier ou abolir la fonction des cellules cérébrales. Il apparait des changements au tracé normal électroencéphalographique, lorsque l'apport d'oxygène au cerveau a atteint un niveau très bas, soit à cause d'une circulation sanguine insuffisante, soit à cause d'une teneur trop faible en oxygène. Bien que plusieurs facteurs peuvent produire les mêmeś modifications sur le tracé électroencéphalographique, il est possible, dans la plupart des cas, d'éliminer un certain nombre de ces facteurs et d'en venir à préciser ce quit, selon toute vraisemblance, produit les modifications sur le tracé. 
Au cours de la chirurgie cardiaquel des épisqdes de ralentissement circulatoire s'ọpservent fréquenment, alors le tracé électroencéphalographique devient un instrument précieux pour avertir l'anesthésiste lorsqu'une fonction vitale est menacée jusqu'à un certain point. Ciet avertišsement survient tardivement car seullement une hypotension ou une bypoxie sénieuse peut produire des modifications sur le tracé électroencéphalographique: Mais il arrive que ces signes apparaissent avant qu'il ne soit trop tard pour prévenir l'apparition d'une lésion. irrêversible ou encore ils peuvent devenir la seule indication pour l'anesthésiste que son malade est dans un état critique. Au cours de la circulation extracorporelle, où plusieurs signes vitaux habituels sont absents; le tracé électroencéphalographique semble être le plus précielux qudice d'une circulation cérébrale adéquate, indice que l'on peut observer à' tous les instants et enregistrer.

Au cours des séries de cas que nous présentions, nous avons noté deux types de tracés électroencéphalographiques en réponse a de l'hypotension: (i) un tracé montrant de grandes ondes lentes, conduisant à une diminution d'amplitude et à uh aplatissement du tràcé, et (ii) une dépresssion rapide des ondes normales, conduisant à l'aplatissement du tracé sans l'apparition d'ondes lentes.

Nous avons présenté des cas qui semblent indiquer quel la vitesse d'apparition de lhypoxie ou de l'hypotension est responsable du typle de réponse. Il peut également exister une différence selon qué le malade est conscient ou. sans ạnesthésie.

Nous avons employé l'ordre des gestes opératoires au cours d'une valvulotomie mitrale pour illustrer la relation qu'il, existe entre l'apparition de l'hypotension et l'apparition des signes électroencéphalderaphiques.' On peut fixer un délai d'environ dix secondes à cause du temps circulatoire et de l'état d'oxygénation.

Au cours d'un moment d'hypotension, chez un malade subissant une valvulotomie mitrale, on a noté des signes électrocardiographiques d'ịschémie du myocarde sans observer de changements sur le tracé électroencéphalographique. En dépit du fait que le cerveau soit habituellement plus sensible que le cour à l'hypoxie, cetté observation démontre combien réduite est la tolérance à l'hypotension chez un cœur malade. Nous concluons, en conséquence, qu'un degré d'hypotension qui ne parvient pas à produire dẹs modifications du tracé électroencéphalographique, ne peut pas, en général, être envisagé de toute sécurité pour tout l'organisme.

\section{REFERENCES}

1. Ajmone-Marsau, C., \& Fuortes, G.J F. Electrographic Study of the Convulsant Action of Intravenously Administered Acetylcholine. EEG \& Clin. Neurophysiol. 1:283 (1949).

2. Asenjo, A. Ueber die Wirkung des Extracranialen Verschlusses der Hirngefässe auf die Bioelektrische Tätigkeit der Hiirnrinde, Zbl. f. Neurochirurgie 4:41 (1939).

3. Aymes, E. W:, Mahony, D. V., \& Goodman, R. D. Adam-Stokes Syndrome and Cerebral Anoxia, J. Nerv. \& Ment. Dis. 117:334 (1953)!

4. BeEchen, H. K., McDonovgr, F. K., \& Forbẹs, A. Effect of Blood Pressure Changes on Cortical Potentials during. Anaesthesia. J. Neurophysiol. 1:324 (1938).

5. Ввомасе, P. R. Some Electroencephalographic Changes Associated with Induced Vascular Hypotension., Proc. Roy. Soc. Med. 46:919 (1953). 
6. Clowes, G. H. A., Jr.; Ketcenger, H. E.; McBuranex, IR. W; \& Sneong, F. A. The EEG in the Evafuation of Anaesthetic Agents and Carbon Dioxdde Accumulation during Surgery. Ann; Surg. 138:558 (1853).

7. Countin, R:F, Bickrord, R. G., F Fulconer, A., Jr; The Classification and Signiticance of Electro-Encephalographic Patterns Produced by Nítrous-Oxido-Ether Anaesthesia during Surgical Operations. Proc. Staff Meet. Mayo Clinic 25:197 (1850).

8. Davis, P. A., Davis, H., \& Thompson, J. W. Progressive Changes in the Hhoman EEG under Low $\mathrm{O}_{2}$ Tensions. Am. J. Physiol. 123:51 (1938).

9. Faitconer, A., Jn. Correlation of Concentration of Ether in Arterial Blood with Electroencephalographic Patterns Occifining during Ether-Oxygen and during Nitrous Oxide, Ether and Oxygen Anaesthesia in Human Surgical Patients. Anesthesiology 13:361 (1952) $:$

10. Finnentx, F. A., Jr., Wrimon, Lroyid, \& Fayeras, J..F. Cerebral Hemodynamics during Cerebral Ischemia Induced by Acute Hypotension. J. Clin. Invest. 33:1227 (1954).

11. Gastaut, H., \& Fischen-WmLiams, M. Electro-Encephalographic Study of Syncope. Lancet II:1018 (1951).

12. Grbes, F. A., Whlua, D., \& Grass, E. - Modification of the Cortical Frequence Spectrum by Changes in $\mathrm{CO}_{2}$, Bloodsugar and $\mathrm{O}_{2}$. J. Neurophysiol. 3:49 (1939).

13. Hale, D. E.; \& MoracA, P. P. Electrocardiogram and Electroencephalogram in Elective Cardiac Arrest. J:A.M.A. 166:1672 (1958).

14. KETY, S. S. : Circulation and Metabolism of the Human Brain in Health and Disease. Am. J. Medicine 8:205 (1950).

15. KuBicrx, $\mathrm{ST}_{\text {, \& \& JusT }}$ O. Das hirnelektrische Bild bei extremer künstlicher Blutdrucksenkung. Der Anestsetist 6:143 (1957).

16. Lurt, U. C., \& Noezí, W. K: The Manifestations of Sudden Brief Anoxia in Man. Rep. \#55-86, School of Aviation Medicine USA, Randoiph AFB, Texas.

17. No,LiL, W. K., Brown, E. S., \& ELAM, .J! O. The Detection of Impairment of Oxygenttion: Encephalography and Oximetry during Surgery. Rep. \#2, USAF School of Aviation Medicine, Randolph Field, Texas (1954).

18. Patrucx, R. T., Theye, R. A., \& Mofrit, E. A. Studies in Extracorporeal Circulation: V, Anaesthesia and Supportive Care during Intracardiac Surgery with the Gibbon Type Pump Oxigenator. Anesthesiology 18:673 (1957).

19. Scrallex, W., \& Warz, D. Effect of Drug Induced Hypotension on the Encephalogram of the Dog. Anesthesiology 15:673 (1954).

20. SPOEREL, W. E. Unpublished data.

21. Stevens, H., \& Fazeris, J. F. Expetimentally Itaduced Hypotension: Clinical and Electroencephalographic Consequences: Arch.| Neurol. Psychiat. 73:416 (1955).

22. ThEYe, R. A., PAtrucx, R. 'T., \& KIRxaIN, J. W. The EEG in Patients Undergoing Open Intracardiac Operations with the Aid of Extracorpareal Circulation. J. Thorac.| Surg. 34:709 (1957).

23. Wyre, B. D. Electrographic Monitoring of Anaesthèsia. Brit. Med. Bull. 14:58 (1958). 